\title{
CHARACTERIZATION OF SULFUR MODIFIED BINDER USING FLYASH AND GGBFS AS FILLER MATERIAL
}

\author{
Kumkum Priyadarsini \\ Veer Surendra Sai University of Technology, Burla, Odisha, India
}

\begin{abstract}
The bitumen is used as binder in bituminous pavements. The heavy growth of traffic loads and their contact tyre pressure with different climatic conditions improve the demand of bituminous flexible pavement. The bituminous pavement failure occurs due to heavy traffic load which can cause higher stress as well as temperature variations on surface of pavement due to which cracking, rutting occurs. To protect the surface course binders from such distresses, binders can be associated with various modifiers which can improve the durability, performance, quality of pavement etc. In this paper locally available sulphur added to the conventional VG 30 bitumen of different percentages i.e. 1 to $9 \%$ to form modified binder. The bituminous concrete mixes of grading -2 accompanying from mid-point gradation using sulphur as modifier. This research work states the physical properties, Marshall Stability test properties of bituminous concrete mixes of VG 30, optimum sulphur content of bitumen using sulphur as modifier. The main objective of the research work is to investigate the effect of addition of sulphur of various percentages on the physical properties and replacement of fly ash as filler in of sulphur modified bitumen to find out optimum fly ash content. This study helps to find out the wholesomeness of sulphur modified bitumen by virtue of which the consumption of plain bitumen can be reduced and also recycling of waste materials.
\end{abstract}

Keywords: Bituminous concrete mixes, Sulfur, Physical properties, Marshall Stability test, Fly ash, SMB

Cite this Article: Kumkum Priyadarsini, Characterization of Sulfur Modified Binder Using Flyash and GGBFS as Filler Material, International Journal of Civil Engineering and Technology (IJCIET), 12(8), 2021, pp. 1-19.

https://iaeme.com/Home/issue/IJCIET?Volume $=12 \&$ Issue $=8$

\section{INTRODUCTION}

Mode of transport is a term used to catagorize mainly different means of conveyance. The different modes of transport are air, water, and land transport, which includes rail, road and offroad transport. Land transport i.e. highways are the basic mode of transportation. A highway pavement is a design layer having different materials on the top of soil sub-grade. The main purpose of highway pavement is to transfer the vehicular loads to the sub-grade soil below. The pavement should strong, durable, skid resistance and ideal light reflecting qualities as well as 
less noise pollution qualities. Bitumen is used as binder in construction of flexible pavements. Although bitumen can be used for a wide variety of applications, the principal use is for the construction of highway and airport pavements, which together account for approximately $85 \%$ of the worldwide consumption of bitumen. Bitumen is a strong binder which have high adhesive property, resistance to water, durable as a result of which it can be used during road construction. It has also capacity to resist actions due to the acids, alkalis and salts. (Minnestona Asphalt Pavement Association, 2003)

Due to increased population, the traffic level increased day by day. To improve the properties of bitumen mixture, bitumen may be modified by certain binders or additives such as crumb rubber, sulfur, polymer etc. There are numerous prominent modified binders available throughout the world. In this research work, sulphur is used as modifier to increase the properties of bituminous mixture. The modified bitumen and the prepared mixture of these modified bitumen should acquires better strength characteristics compared to the mixes with virgin bitumen. This study is focusing towards the modification of Virgin Viscosity grade VG 30 bitumen with sulphur available in local market and also improvisation of the properties of SMB with replacing conventional filler stone dust with non-conventional filler Fly ash as well as recycling the waste materials like sulphur and fly ash to reduce the environmental pollution.

\section{PROBLEM STATEMENT}

Recently, 70 million tones Sulfur is produced Worldwide. The Enormous quantity of sulfur manufacturing act as a subsidiary product in petrochemical as well as gas \& oil refining industries and its less usage in the country has been a great problem. The oil refineries in public sector reported production of sulfur during the year 2015-16, Indian Oil Corp. Ltd contributed about $87 \%$ of the total production during the year. Among the states, Haryana accounted for $41 \%$ of the total sulfur production, and it was followed by Gujarat 23\%, Maharashtra 13\%, Uttar Pradesh $11 \%$, West Bengal $10 \%$ and the remaining $2 \%$ production was contributed by Bihar and Assam. The production of sulfur recovered as a byproduct from fertilizer plants and oil refineries was 441 thousand tons in 2015-16 as against 429 thousand tons in the preceding year. The total consumption of elemental sulfur in 2015-16 was about 1.16 million tones. To overcome such issue as well as good properties of Sulfur and also for recycling the waste and protect the environment from pollution, the exertion of sulfur is necessary. So in this work, we utilize sulfur modifier to enhance the bituminous mix properties.

At presently, India has being produced roughly about 960 million tons of misuse solids per year just as byproduct from industrial, mining, municipal, farming and more sectors. Out of these amount, organic wastes are 350 million tons from agricultural field, 290 million tons are industrial organic waste and mining zones along with 4.5 million tons are hazardous in nature. The production of wastes from coal plant comprises more than 125,000 tons of coal ash, which contains fly ash and bottom ash and only inside India total 95 million ton amount of fly ash has been produced each year which will absorb nearly 65000acres of land. So an attempt should be made to solve the problem caused due to the dumping of Fly ash in front of the plant which affects the environment severely. Annually in India, around 10 million tons of Blast furnace slag is produced as a byproduct of steel and iron Industries. Therefore exertion of these industrial wastes should be made.

\section{OBJECTIVES OF RESEARCH}

The objective of project has been visualizing about attempt towards proposing a stable surface by utilization of Sulfur Modified Binder and observing the performances of SMB by replacing the wastes named just as Fly ash and GGBFS as filler with determining the optimum dose of Bitumen, Sulfur, Fly ash as well as GGBFS at specific mixing temperatures by using Marshall 
Stability test and checking the physical properties between conventional mix with Sulfur Modified Mix.

\section{SOME PREVIOUS RESEARCH WORK}

Many investigator have shown their concern towards the study of the properties of modified binder and comparing it with virgin bitumen. The followings are the research works carried out on SMB by some important researchers:

Poorna Prajna S, Mohamed Ilyas Anjum (2015) states that the bituminous concrete mixes using midpoint gradation for aggregate combined index of $30 \%$ using sulfur as modifier. They investigate the conventional Marshall Stability test properties of $60 / 70$ grade of bitumen modified with $3 \%, 6 \%, 9 \%$, and $12 \%$ of sulphur modifier [1].

Praveen Kumar and Md.Tanveer Khan (2015) suggests that the accession of sulphur to the bitumen can increase the quality of bitumen and strengthen its properties as well as its use in construction of road. In this work the consequence of accretion of sulphur on the physical properties of the bitumen was studied and the optimum dose of sulphur which would be added to the bitumen was ascertained and aging effect of Sulphur modifier also investigated. [2].

VAHID REZVANI et al. (2015) investigates the characteristics of limited interchange of bitumen with the addition of sulfur in the bituminous mixture. The comparison between the properties of conventional bitumen and sulfur modified bitumen was conducted. The process of adding sulfur with neat bitumen and then make the mix of it with aggregate and finally optimized condition of sulfur modified asphalt formation concerning towards atmospheric problems have been explained [3].

HARPAKSINH J.RAOL et al. (2015) focuses on "effect of aging on the physical and Rheological Properties of bitumen binder incorporated with sulfur and waste plastic". He states about "physical and rheological" property of Virgin binder blending amongst different percentages of sulfur ( $0 \%$ to $2.5 \%$ ) and plastic waste (2\% to $10 \%)$.The Optimum modifier content also identified from both modifiers are determined by Marshall Stability test which is $2 \%$ for sulfur modifier and $8 \%$ for plastic waste and the effect of aging and Rheological properties are determined by TFOT and DSR test. They conclude that the properties increases with addition of modifier to the binder while rheological and aging properties are

within the permissible limit and from Marshall Stability experiment outcomes, Observation should be made that stability and Flow results rises on admixing sulfur and waste plastic to the bituminous mix [4].

MAHABIR PANDA et al. (2016) investigates the development and evaluation of sulfur modified bituminous binder. They use sulfur as modifier on VG 30 bitumen from percentage variation 1 to $8 \%$ at 90 to $140^{\circ} \mathrm{c}$. They check rheological properties of modified and unmodified binder using Dynamic shear Rheometer (DSR) test. They found that $2 \%$ sulfur at $120^{\circ} \mathrm{c}$ gives better rheological properties as compared to other percentage of sulfur and the modified binder provides appropriate result as compared with unmodified bitumen [5].

\section{MATERIALS USED IN RESEARCH WORK}

Bitumen - Bitumen is dark black or brown in color possessing adhesive and viscous qualities due to which it should be suitable for using in construction of pavement. Bitumen of viscosity grading 30 is used as binder in this research work.

Aggregate- Aggregates are an eminent part in the construction application. Both coarse and fine aggregates are used in this research work. 
Sulphur- Sulfur is a chemical material with symbol S with atomic number 16. Sulfur is bright yellow in color and crystalline solid at room temperature. Sulfur reacts with every element except with gold, platinum, iridium, tellurium and the noble gases. Here we use sulphur as modifier in bituminous mixture.

Filler- Fly ash and Ground granulated blast furnace slag (GGBFS) is used as filler in this research work. Fly ash is a by-product of flaming crushed coal. Ground Granulated Blast Furnace slag (GGBS or GGBFS) has acquired from destroying molten iron slag.

\section{OBJECTIVE OF THE WORK}

The objective of project has been visualizing about attempt towards proposing a stable surface by utilization of Sulfur Modified Binder and observing the performances of SMB by replacing the wastes named just as flyash and GGBFS as filler with determining the optimum dose of Bitumen, Sulfur, Fly ash as well as GGBFS at specific mixing temperatures by using Marshall Stability test and checking the physical properties between conventional mix with Sulfur Modified Mix.

\section{METHEDOLOGIES}

Selection of materials: The materials selected for this research work were various sizes of aggregates, Bitumen (VG 30), Modifier (sulfur), Fillers (Stone dust, Fly ash \& GGBFS). In this research work 60/70 (Vikash Refiner HP Asphalt VG 30) used as virgin binder and Sulphur powder is used as Modified binder in addition with VG 30 bitumen. Sulfur was collected from "Scientific Supplier, Sambalpur". The various sizes of aggregates were collected from institute laboratory.

Property tests on materials: After selecting all the materials for research, the materials physical properties have to be checked through the available instrument in the university laboratory and some other tests were conducted on IIT, Bhubaneswar. The properties of aggregate, bitumen with viscosity grading bitumen as well as sulfur modified bitumen with aging has also be checked whose results were shown in result analysis parts.

Gradation of aggregates: In this research work BC gradation is conducted. In MORT\&H the BC grading for grade 1 and 2 are mentioned. But in my work BC grading 2 with nominal size 19 $\mathrm{mm}$ is used. The figure below shows the gradation chart.

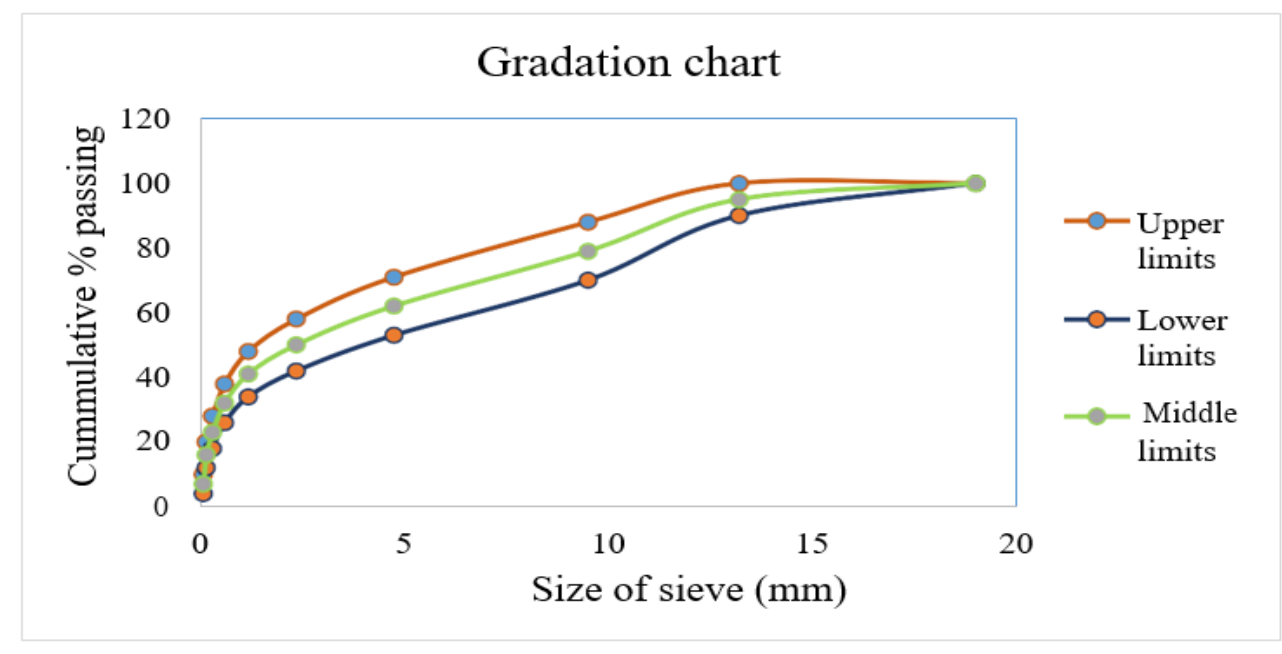

Figure 1 
Mix design using stone dust as filler in unmodified and modified bitumen: The bituminous mix is conducted to decide ratio of amount of Bitumen, Fine Aggregate, Coarse aggregate and Filler for making a mixture that provides workable, hard, long lasting with reasonable road. This portion is most important for research. Bitumen mix is prepared as per marshall Test procedure with control mix having binder content $4 \%, 4.5 \%, 5 \%, 5.5 \%$, and $6 \%$ respectively. After that the specimen is tested with Marshall stability experimental instrument to determine Stability, flow of sample.

Mix design using fly ash as filler in SMB at OSC: Then the SMB mixes are prepared up to 0.5 to $4 \%$ of sulfur content and bituminous mix were prepared and test results obtained from Marshall stability test. The complete aim for mix design of bitumen is procuring OBC. I obtained Optimum bitumen content of conventional mixture by using Stone dust in place of Filler and OSC for SMB mix and By utilizing Fly ash and GGBFS as filler on OSC, the OFC and OGGBFSC (4 to 10\%) as per MORTH specifications is determined.

Water sensitivity with TSR test: By obtaining OBC, OSC, OFC \& OGGBFS, the next step is to check the Indirect tensile strength test with checking tensile strength ratio. This test is conducted by two group of specimens which is known as Conditioned (wet) sample and unconditioned (dry) specimen for investigating the impact of wateriness over Virgin bitumen and SMB and this is illustrated as Tensile strength ratio (TSR). ITS have been determined by the following mathematical formula:

$$
\mathrm{ITS}=\frac{2000 \times P}{\pi \times h a v g \times d}
$$

\section{RESULT ANALYSIS}

\subsection{Properties Tests on Bitumen and Sulphur Modified Bitumen}

\section{Penetration Test (IS 1203 1978, IS 73 2006)}

The bitumen is heated about $75^{\circ} \mathrm{C}$ to $100^{\circ} \mathrm{C}$ above this temperature bitumen gets softer. Bitumen specimens is appropriately mixed for making this free from water and air bubbles. Then the sample is poured to $35 \mathrm{~mm}$ depth and then keep the sample for air cooling in atmosphere at 15 to $30^{\circ} \mathrm{C}$ for about 60 to 90 minutes and then sample is placed inside control Water Bath at $25^{\circ} \mathrm{C}$ about $60-90$ minutes.

Then the sample is removed from water bath with keeping it beneath the needle attached with penetrometer. Lowering of needle set up is done through the adjusting screw and point of needle has just contact the upper portion of bitumen kept in cup and clamp has fixed. The initial reading of penetrometer is taken before releasing the needle. By pressing the knobs of penetrometer, the needle is released about a period of 5 seconds and end results are observed by "Dial gauge". Removed the needle and then clean and dry the needle. By the same procedure three such measurements are taken and the average of three measurements is taken as penetration value. It is represented in $1 / 10$ th in $\mathrm{mm}$.

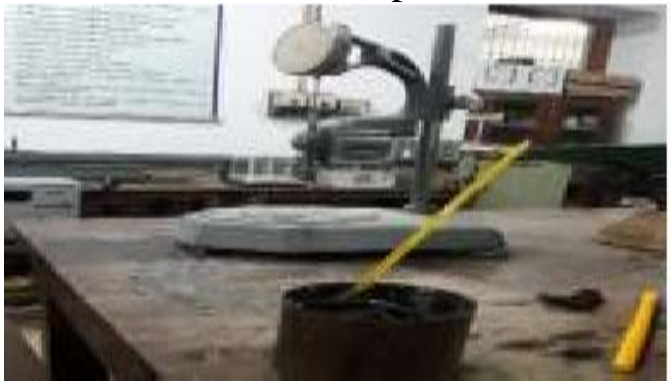

Figure 3.5 (a) Test on penetration

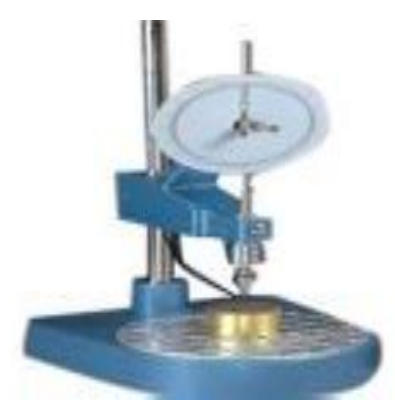

Figure 3.5 (b) Penetrometer 


\section{Softening Point Test}

The bitumen sample has been preheated around a temperature of 75 to $100^{\circ} \mathrm{c}$ temperature just before it is fully converted in to fluid form. Then rings are heated with outpouring hot bitumen keeping it on a plate of metal. For staying away from adhering of binder, solution of glycerin and dextrin coating is done to this. The rings are kept for air cooling about $30 \mathrm{~min}$, then surplus binder is cut down and circular ring has kept on stand with keeping heat of pure water about $5^{\circ} \mathrm{c}$ preserved about 15 minute. Then balls are put on binder from top. Degree of heat in which bitumen impartially contacts metal plate base known as "Softening point" and two observations are taken and their average is taken as result.
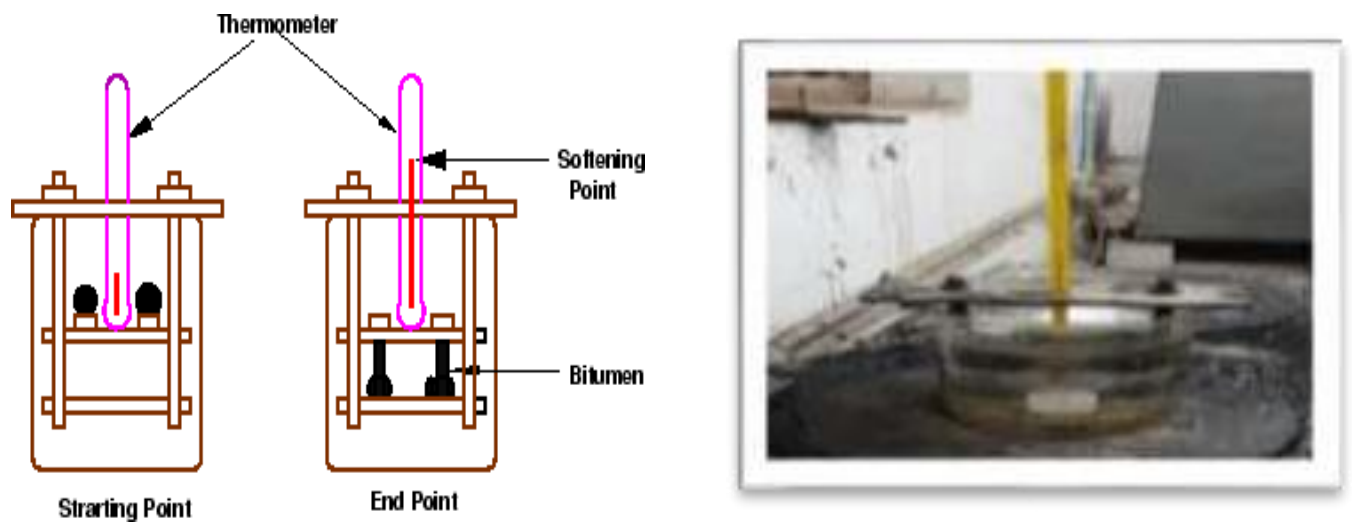

Figure 3.6 (a) Total set up of softening point test Figure3.6(b)Test conducted on lab

\section{Ductility Test}

Bitumen has been liquefied around temperature of 75 to $100^{\circ} \mathrm{c}$ until it has converted to fluid. Sample has kept on an assembly of mould with keeping over brass plate with applying Glycerin solution and dextrin around entire mould surface contact with binder. The sample is kept for air cooling in room temperature for 30 to 40 minutes and then placed the sample about $27^{\circ} \mathrm{c}$ around 30 minute inside a water bath. Extra sample has lacerated with the help of warm cutting tool for levelling the outward portion of binder. Thereafter again bitumen has been placed inside the water bath about $27^{\circ} \mathrm{c}$ about $85-95$ minute. Initial reading is set as zero by the pointer mark and then machine gets started. The exact point where strand of sample has been breaking up and the distance between initial and that point, is denoted in cm known as ductility value.

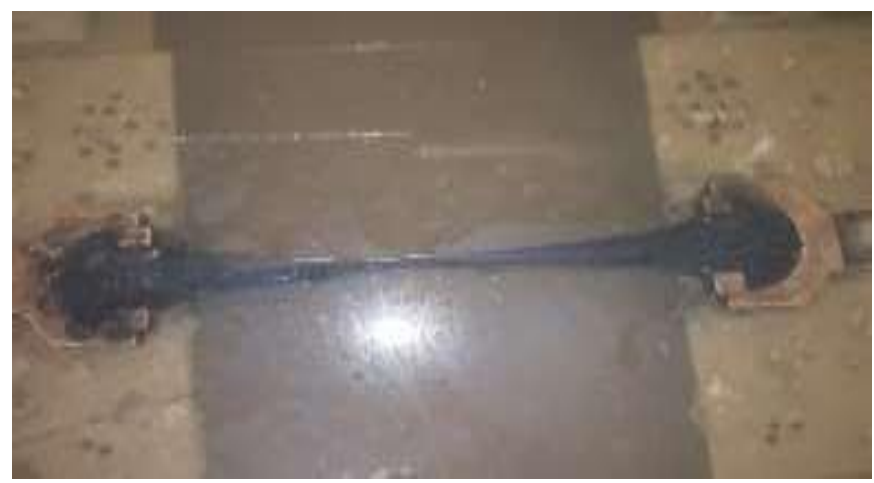

Figure 3.7 Elongated portion of binder on ductility machine. 


\section{Elastic Recovery test}

The sample preparation of this test is to be done as per ductility test but in the elastic recovery Mould. The sample is elongated at the specified "rate of $50 \pm 2.5 \mathrm{~mm}$ per minute" at the specified temperature to a deformation of $10 \mathrm{~cm}$. After $10 \mathrm{~cm}$ deformation, the specimen is cut in to two halves at the mid- point using scissors. The sample is kept on water bath for one hour at certain temperature. After 1 hour, we observe that the elongated part of specimens is come back to its original positions so that both half of samples touch each other. This length of the recombined specimen is measured as " $\mathrm{D}$ " $\mathrm{cm}$.

$100(10-D)$

Elastic Recovery (\%)

10

Where $\mathrm{D}=$ Length of recombined sample in $\mathrm{cm}$.

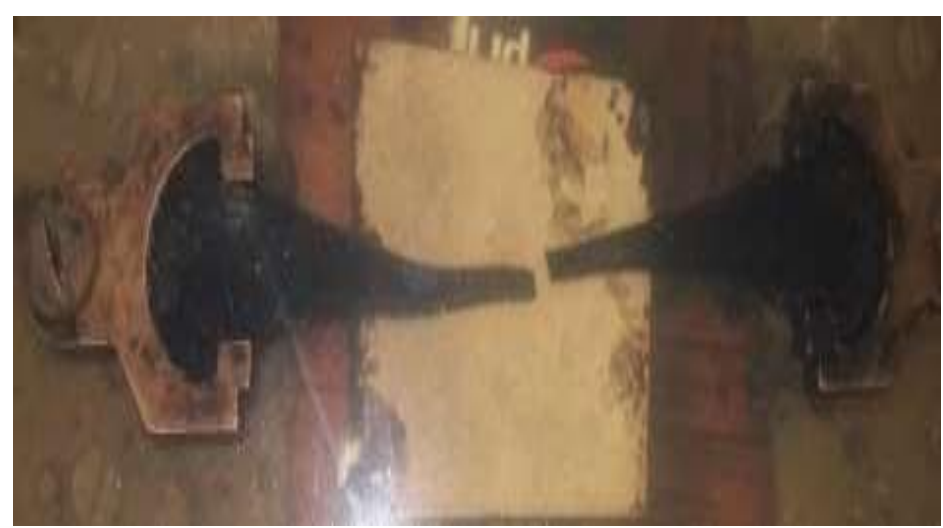

Figure 3.8 Elastic recovery sample with cutting in to two halves

\section{Rolling Thin Film Oven Test}

During RTFOT, $35 \mathrm{gm}$. samples are loaded on the jar and kept for 85 minutes at $163^{\circ} \mathrm{C}$ on R.T.F.O machine. Remove the jars and make it cool up to certain time and clean the jar by removing the samples from jar. The percentage loss of sample is also checked out. The effect of heat and air can be obtained by conducting physical tests after and before the oven treatment.

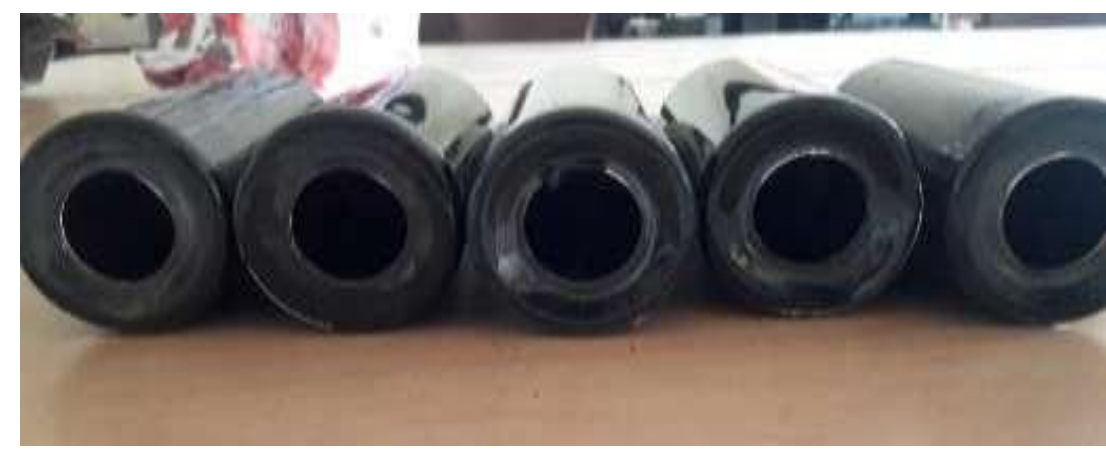



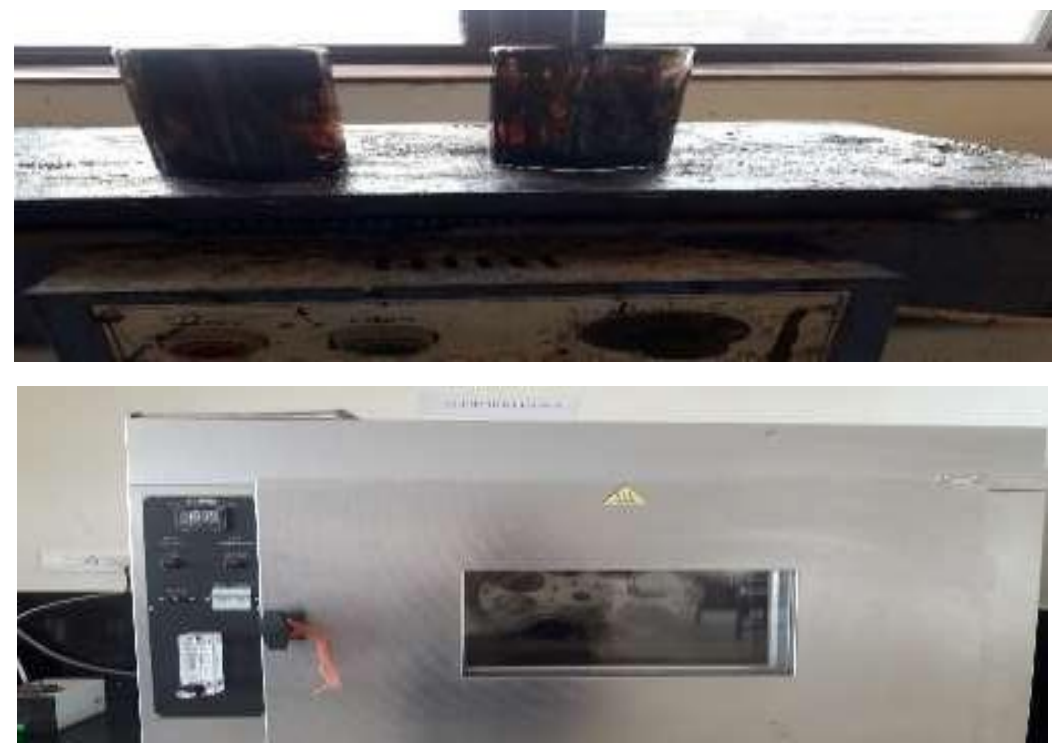

Figure 3.9 (a) Heated sample on jar, Figure 3.9(b) Heating of samples with glass jar on hotplate, Figure 3.9(c) Samples rotating on RTFO machine.

\section{Pressure Aging vessel (PAV) Test}

This provides simulated long term aged bituminous binder for testing the physical property. Bituminous binder is liable to heat and pressure to reproduce in-service aging over a period of 7 to 10 year. PAV procedure takes RTFO samples by heating and placing them in stainless steel pans and then ages them for 20 hours in PAV testing vessel which is pressurized with $2.10 \mathrm{Mpa}$. Then this samples are stored for using in physical property tests.

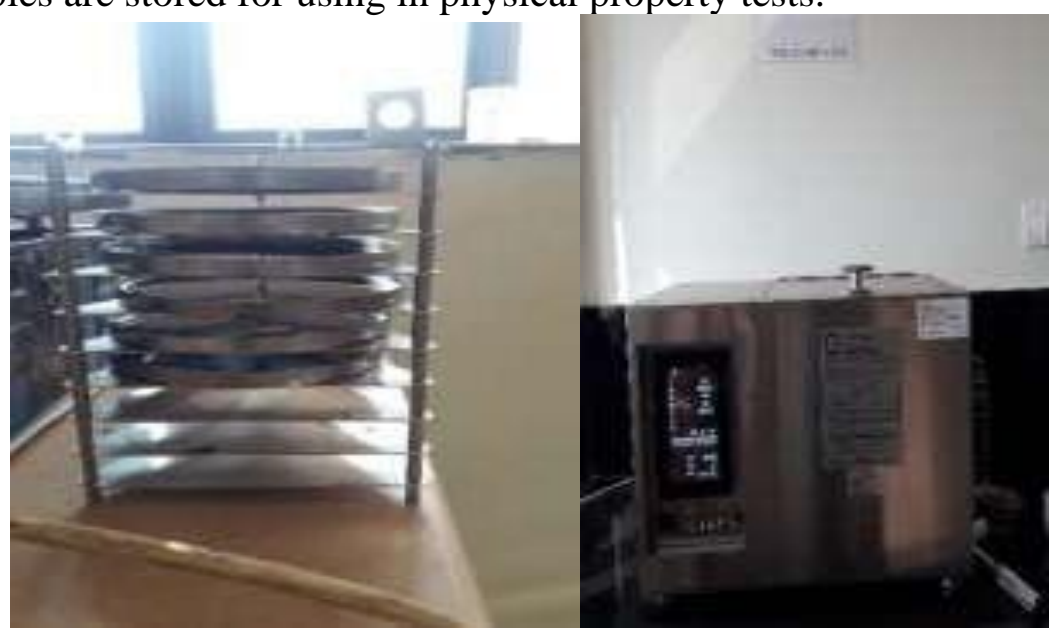

Figure 4

Table 1 Properties of Virgin Bitumen

\begin{tabular}{|l|c|c|c|}
\hline \multicolumn{1}{|c|}{ Tests conducted } & Test Method & Obtained result & Standard results \\
\hline $\begin{array}{l}\text { Penetration }\left(25^{\circ} \mathrm{c}\right)\left(1 / 10^{\text {th }} \text { of }\right. \\
\text { milimeter })\end{array}$ & IS 1203 1978, IS 73 2006 & 65 & $50-70$ \\
\hline Softening point & IS 1203-1978, IS 73 2006 & 46.5 & $40-60$ \\
\hline Ductility & $\begin{array}{c}\text { IS 1203-1978, IS 73 } \\
2006, \text { IS 73 } \\
1961\end{array}$ & 74 & Minimum 40 \\
\hline Elastic recovery & IRC SP 53 2001 & $10 \%$ & $60 \%$ \\
\hline Specific gravity & ASTM D 70 & 1.01 & $0.97-1.02$ \\
\hline
\end{tabular}


Table 2 Properties of Sulfur Modified Binder $(0.5-4 \%)$

\begin{tabular}{|l|c|c|c|c|c|c|c|c|c|}
\hline \multirow{2}{*}{ TESTS CONDUCTED } & \multicolumn{8}{|c|}{ OBSERVED RESUT (O.5-4\%) SULPHUR } & \multicolumn{2}{c|}{$\begin{array}{c}\text { SPECIFIED } \\
\text { RESULTS AS PER } \\
\text { IRC:SP:53-2010 }\end{array}$} \\
\cline { 2 - 9 } & 0.5 & 1 & 1.5 & 2 & 2.5 & 3 & 3.5 & 4 & INTENT \\
\hline $\begin{array}{l}\text { Penetration at } 25^{\circ} \mathrm{C}, 0.1 \\
\text { mm }\end{array}$ & 65 & 64 & 63 & 59 & 57 & 56 & 54 & 52 & 50 to 80 \\
\hline Softening point $\left({ }^{\circ} \mathrm{C}\right)$ & 54.5 & 55.5 & 56 & 56.5 & 57 & 59 & 60.5 & 63 & Minimum 55 \\
\hline $\begin{array}{l}\text { Ductility (mm) } \\
\text { Elastic recovery of half } \\
\text { thread in } \\
\text { Ductilometer }(\%)\end{array}$ & 71 & 68 & 62 & 58 & 55 & 53 & 52 & 51 & Maximum 100 \\
\hline
\end{tabular}

\section{COMPARISON CHART OF PROPERTIES OF VIRGIN BITUMEN WITH SMB}

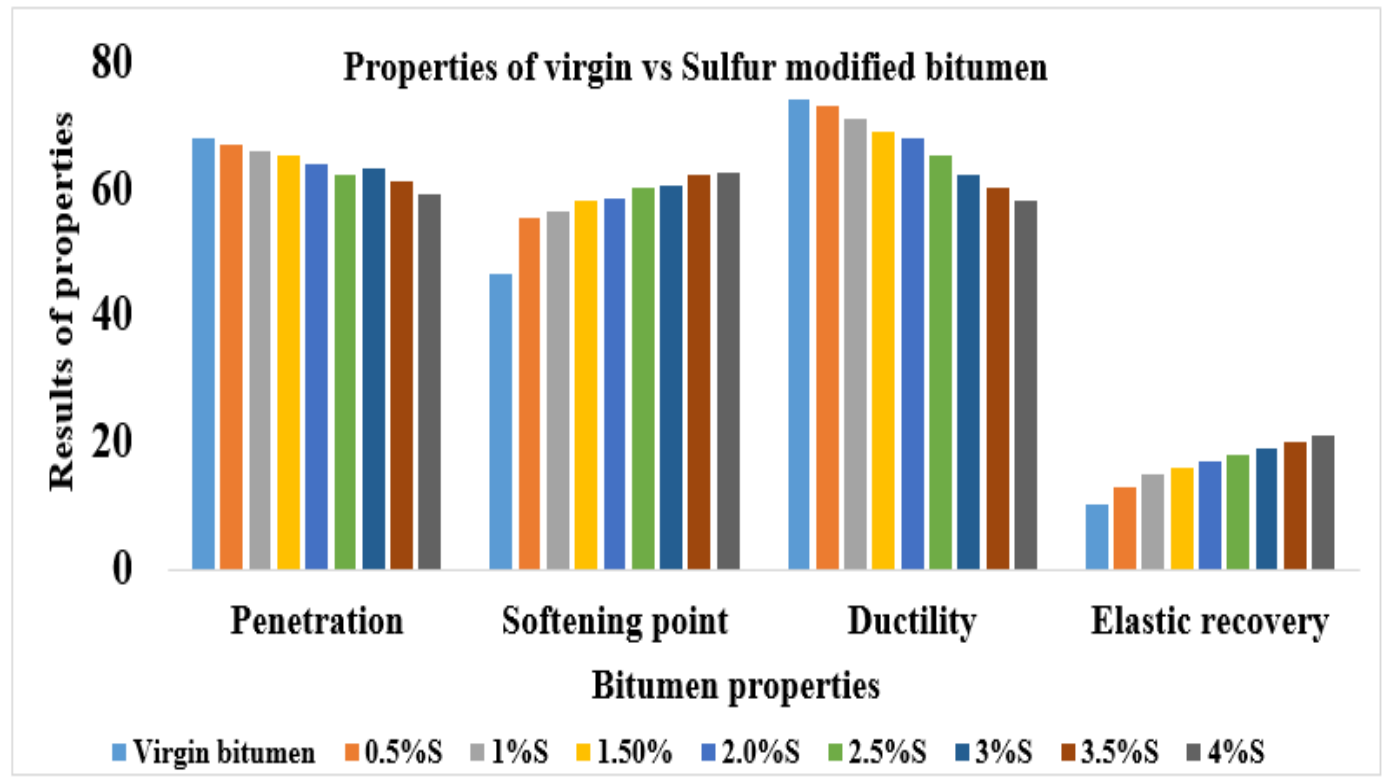

Figure 5

\section{Discussion}

- It is found that the asphalt binder properties increases with addition of modifier content (Sulfur).

- The penetration value gradually decreases with increase in percentage of sulfur content which shows the bitumen gradually hardens.

- The softening point value is higher than neat bitumen which is used in hot climate and specify hardness of bitumen.

- The effect of aging in SMB $(2 \% \mathrm{~S})$ provides better results than virgin bitumen and the results has been with in the permissible limit. 


\section{COMPARISON OF MARSHALL PROPERTIES OF CONTROL MIX WITH SULFUR MODIFIED MIX (0.5 TO 4\%) USING STONE DUST AS FILLER}

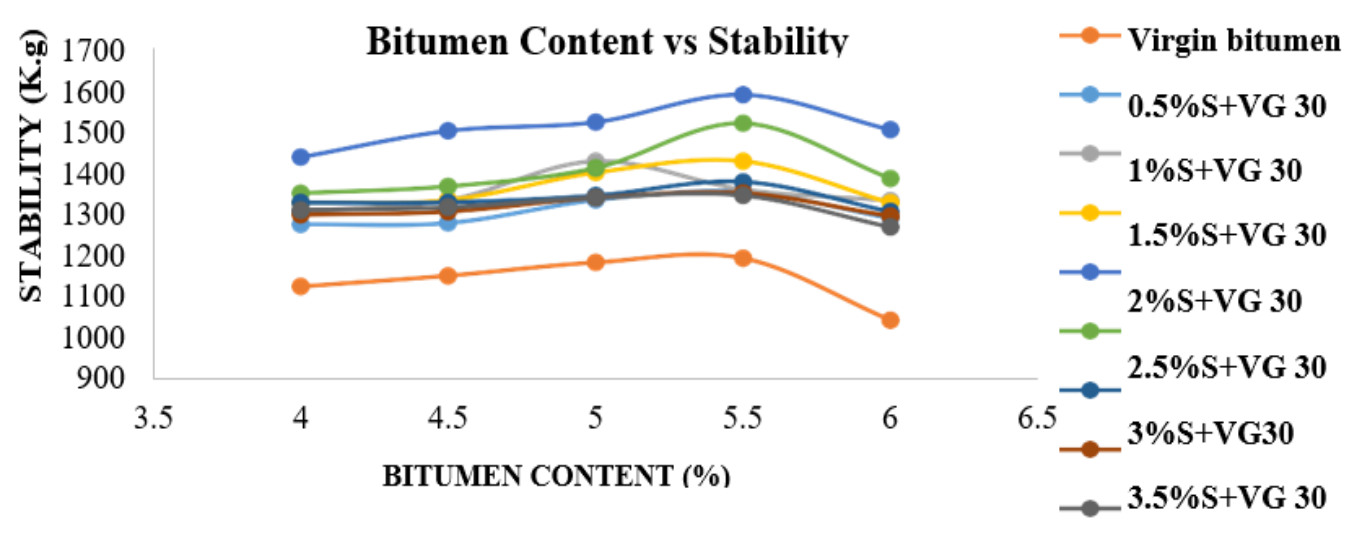

Figure 6

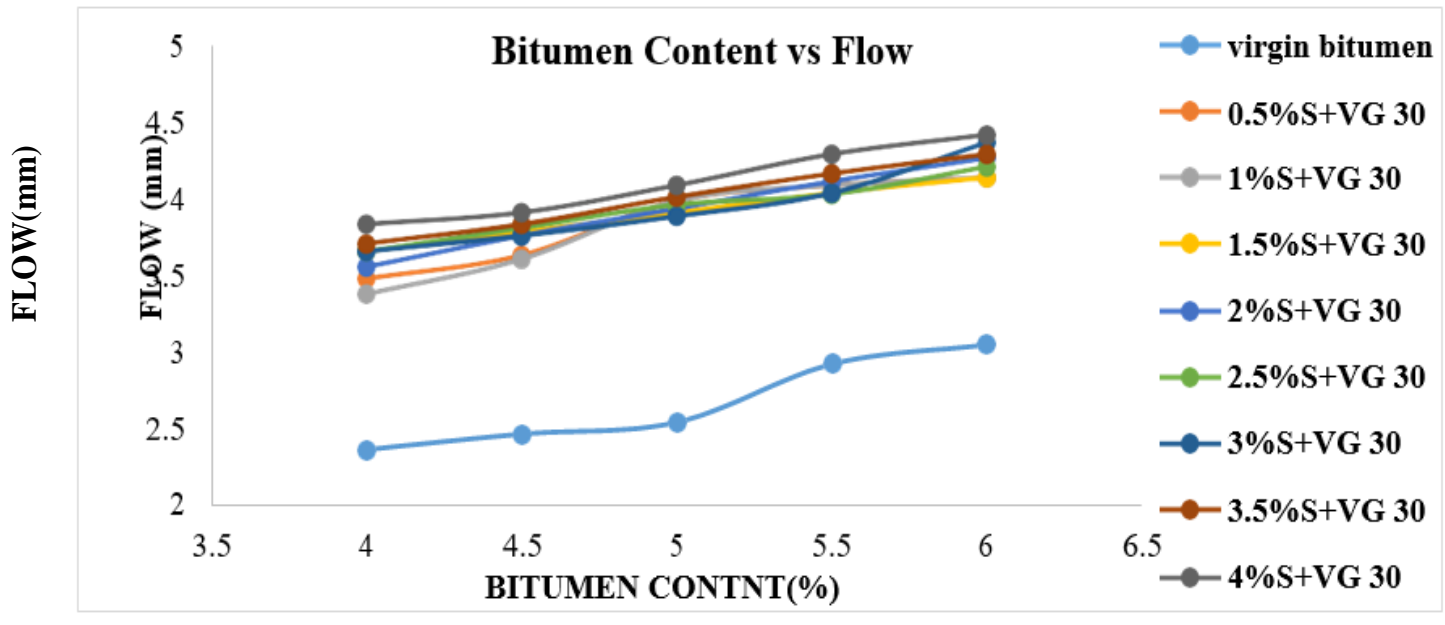

Figure 7

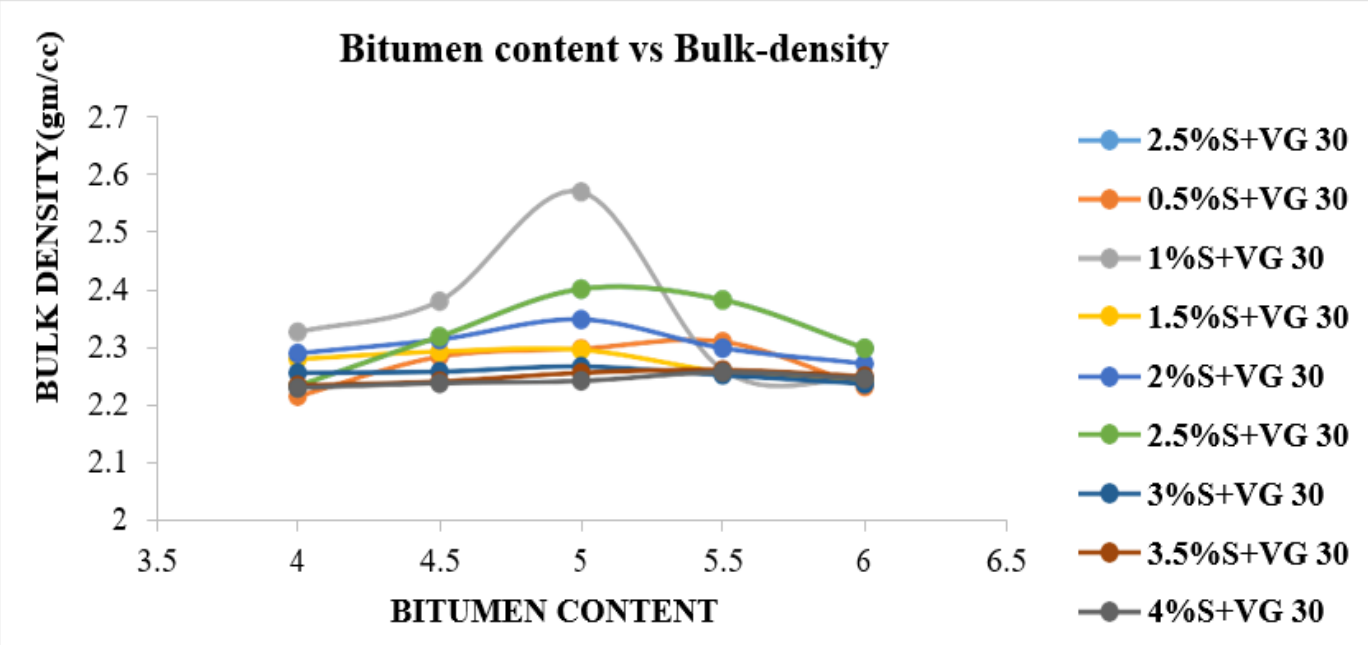

Figure 8 


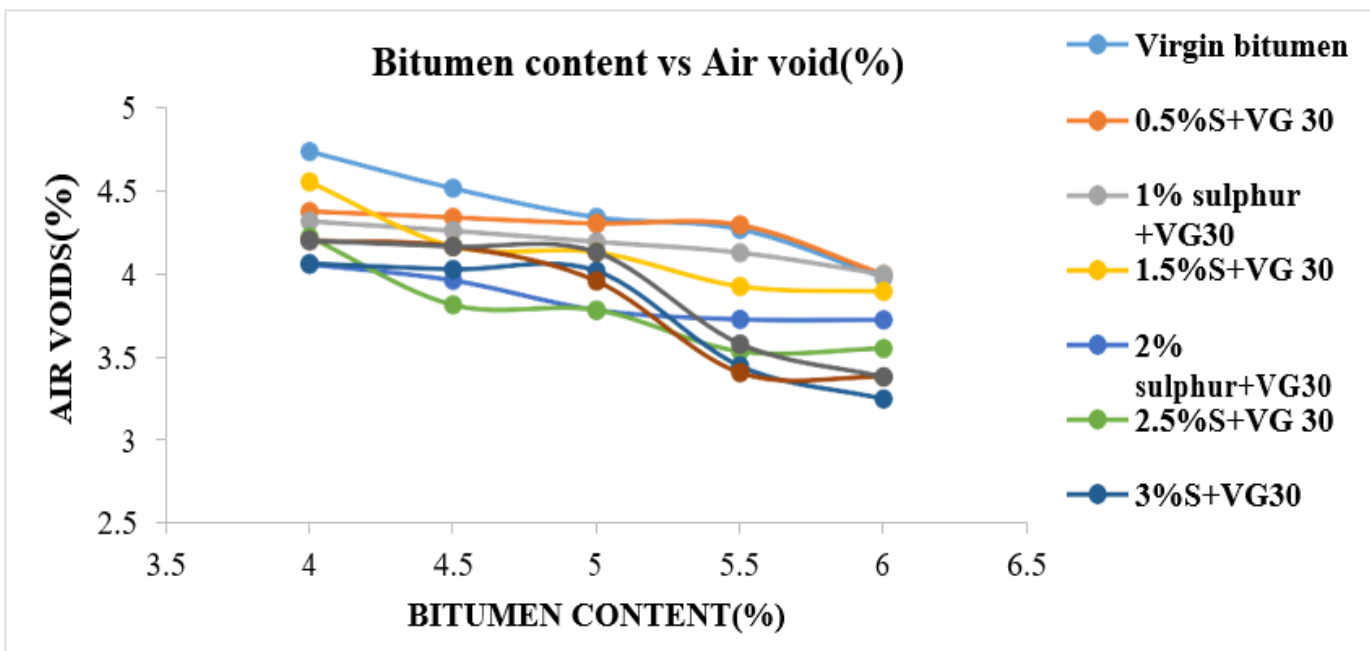

Figure 9

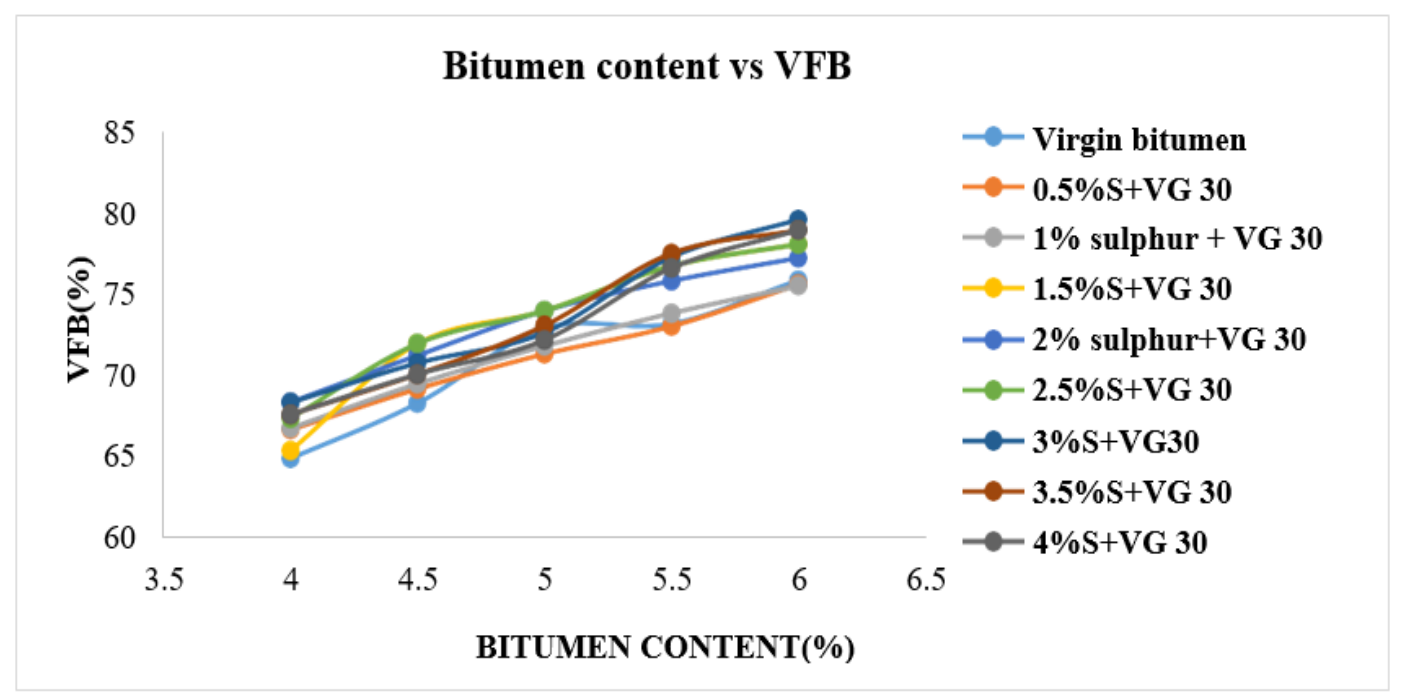

Figure 10

\section{VARIATION OF OBC DUE TO VARYING SULPHUR CONTENT}

Table 3 (Optimum bitumen content with varying \% of modifiers)

\begin{tabular}{|c|c|}
\hline Modifier content(\%) & Optimum bitumen content(\%) \\
\hline 0 & 5.483 \\
\hline 0.5 & 5.67 \\
\hline 1 & 5.5 \\
\hline 1.5 & 5.3 \\
\hline 2 & 4.93 \\
\hline 2.5 & 4.95 \\
\hline 3 & 5.03 \\
\hline 3.5 & 5.3 \\
\hline 4 & 5.41 \\
\hline
\end{tabular}




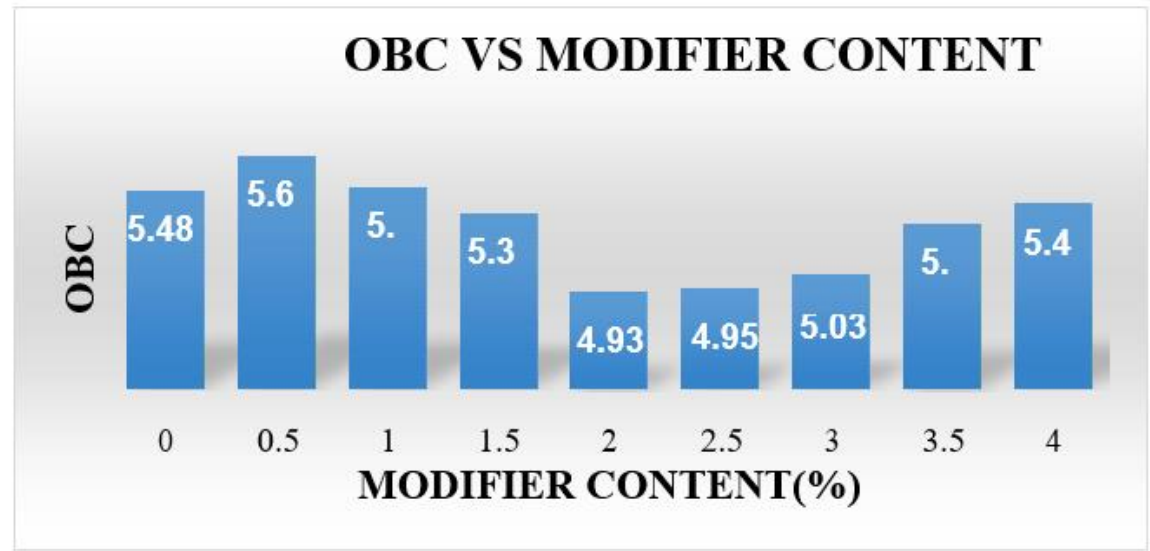

Figure 11

\section{Discussion}

- The highest stability found as $1574.758 \mathrm{~kg}$ when $2 \%$ sulfur has been added with bitumen. The $2 \%$ Sulfur addition provides better stability correlating with control mix and other percentages from SMB.

- Flow results gradually increases with increase in sulfur content but flow for each percentage of sulfur $(0.5-4 \%)$ has been with in the permissible limit.

- The air-void is contrarily interrelated with the Sulfur content. Including the addition of Sulfur amount, the air voids reduces gradually and the density of the Specimens rises with rising in sulfur amount up to a particular extent, then it reduces gradually.

- The Optimum sulfur content is found to be $2 \%$ of the total weight of aggregate which have optimum bitumen content $4.93 \%$.The bitumen content value reduces up to $2 \%$ sulfur content as per fig 5.1.5. Though sulfur reduces bitumen content by creating aromatic Naftens group with bitumen. After $2 \%$ sulfur addition up to $4 \%$ sulfur it will be increased in a certain trend.

- Though 2\% sulfur content bituminous mix provide better Stability, flow, air void as well as VFB value with in the specified limits as per MORTH as compare to other percentages of sulfur content, it should be taken as Optimum sulfur content(OSC).

\section{FLYASHANDGGBFFSREPLACEMENTONOPTIMUMBITUMENAND SULFUR CONTENT}

The filler replacement of Fly ash and GGBFS on virgin bitumen with optimum bitumen content $5.483 \%$ in bituminous mixture should be conducted by Marshall Mix of 4 to $10 \%$ of filler as per MORTH Specification. The followings are the tables and graphs of the results obtained from tests on Marshall Mixture: 


\section{COMPARISON OF MARSHALL PARAMETERS WITH DIFFERENT FILLERS (STONE DUST, FLY ASH, GGBFS)}

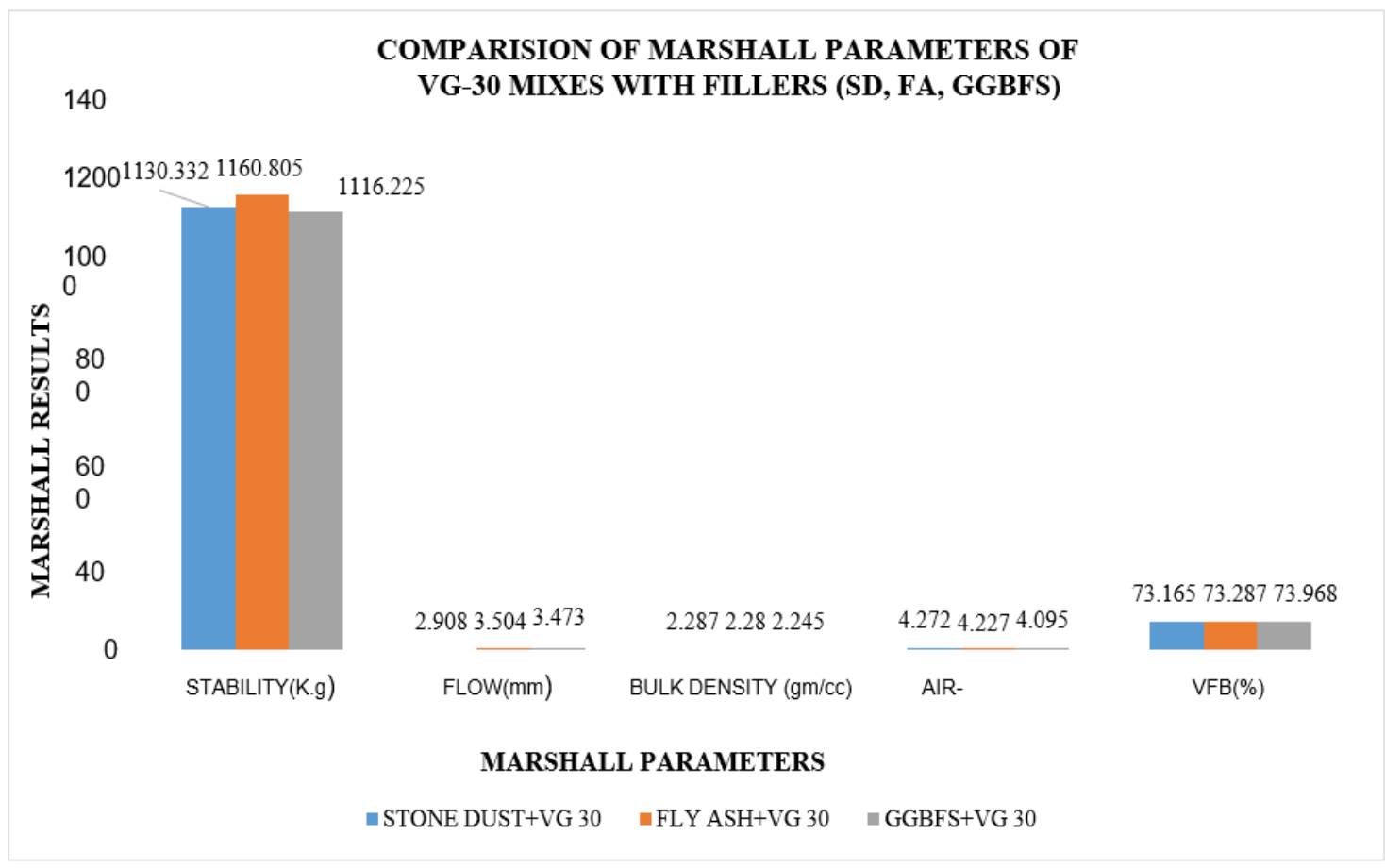

Figure 12

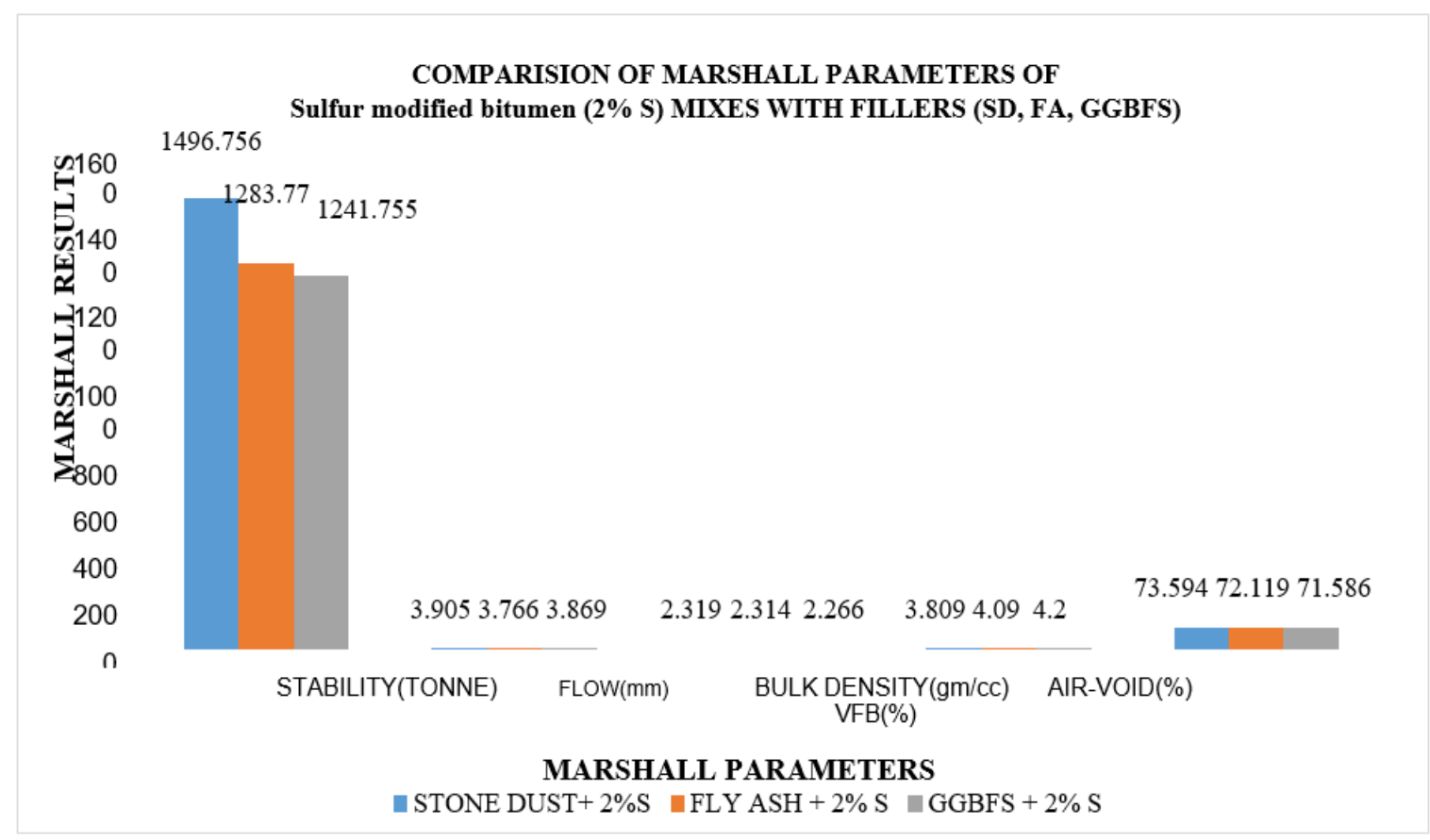

Figure 13 


\section{Indirect Tensile Strength Results on OBC, OSC, OFC and OGGBFSC}

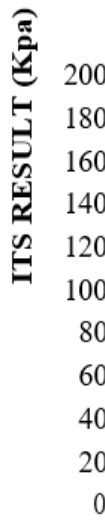

UNCONDITIONED ITS RESULTS FOR VG 30

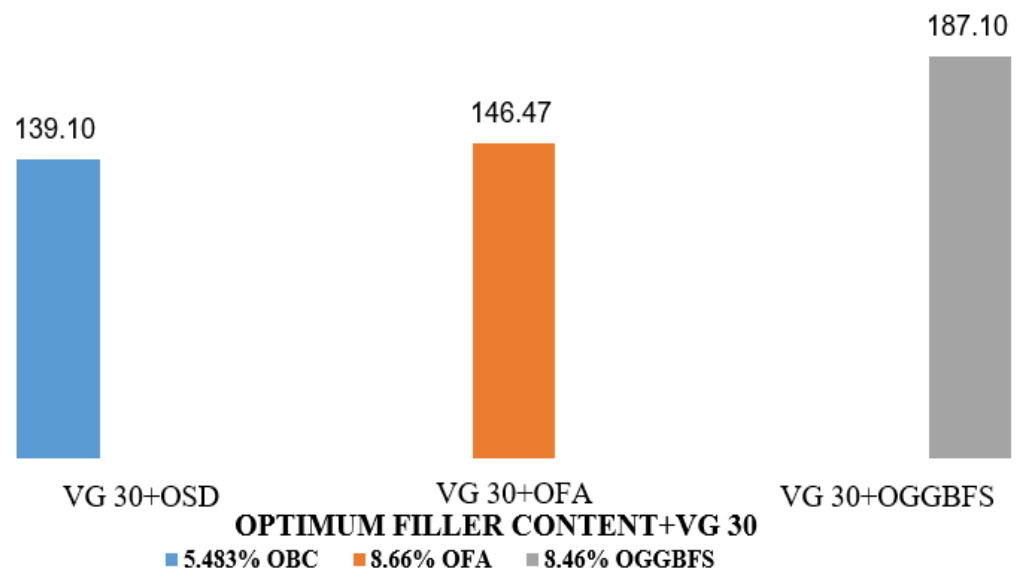

Figure 14

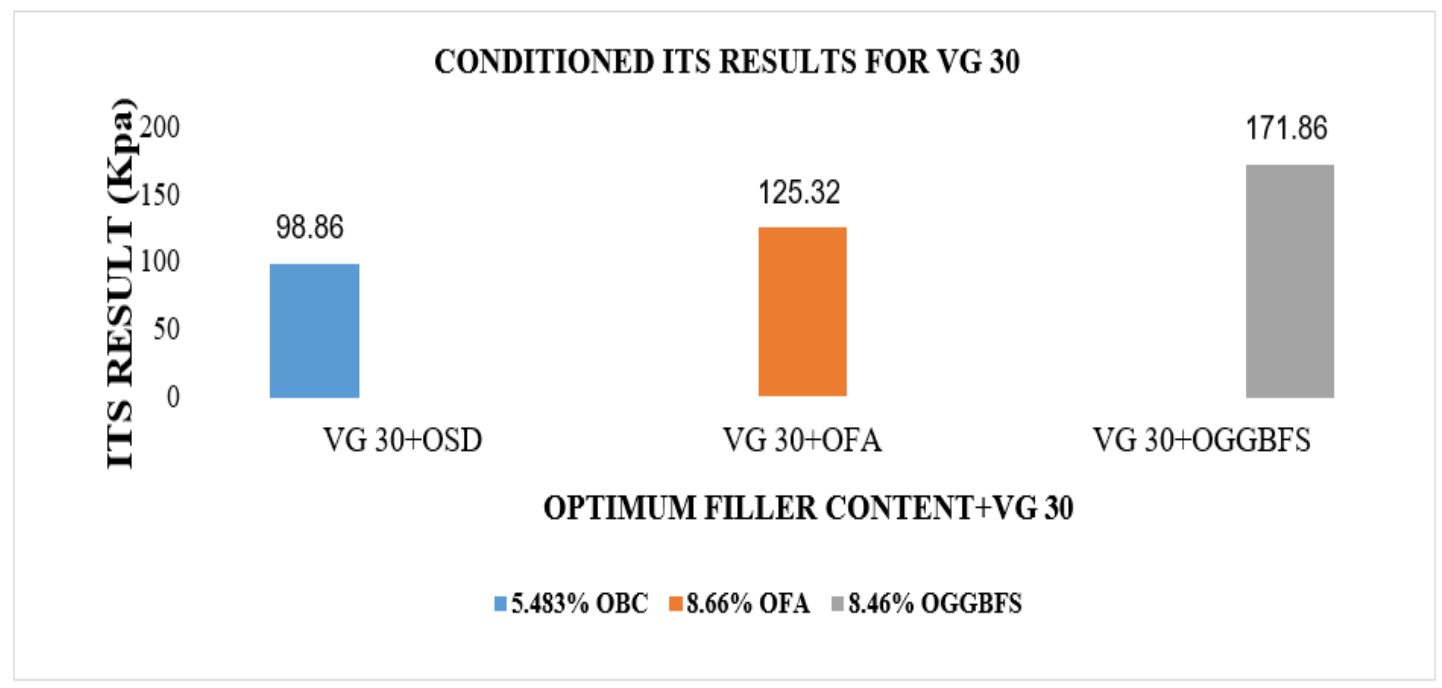

Figure 15

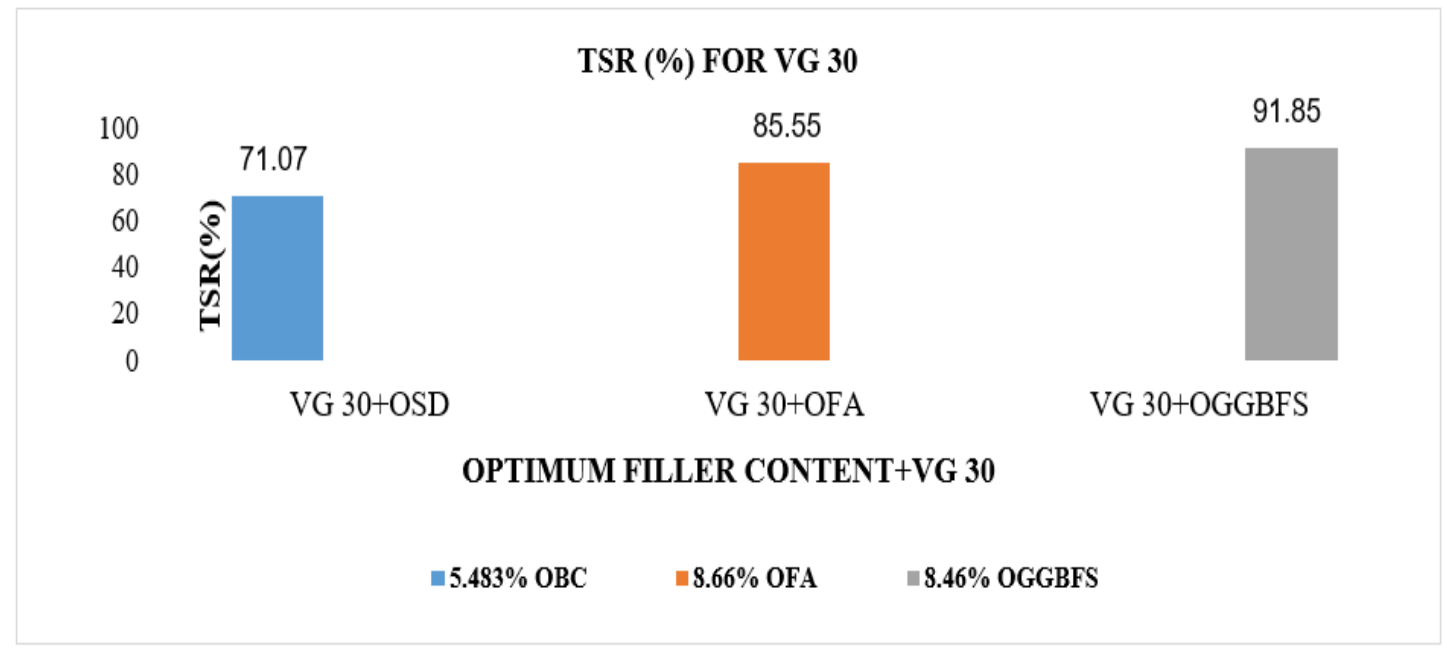

Figure 16 


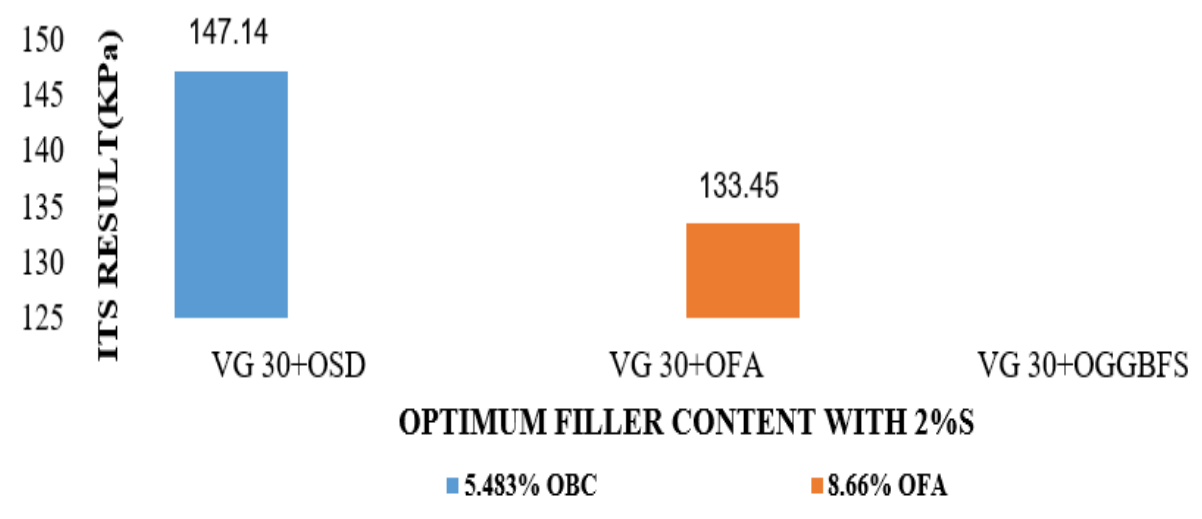

Figure 17

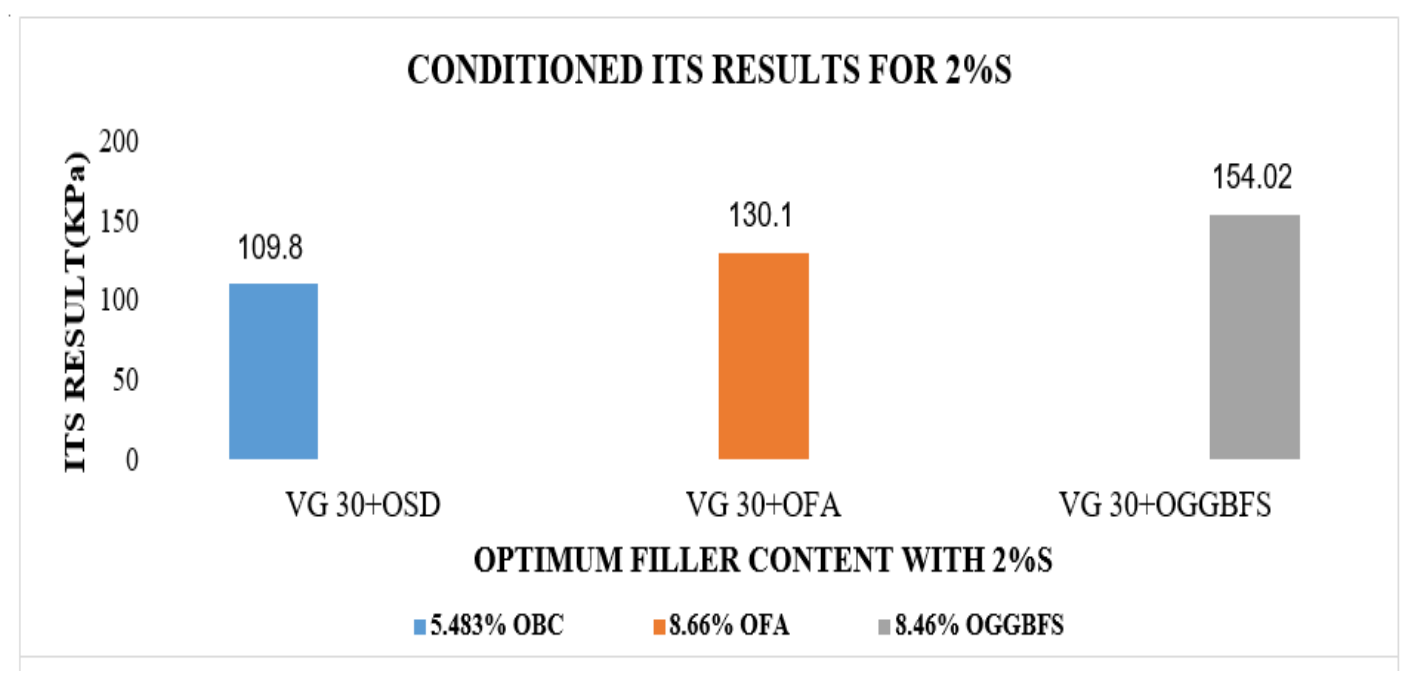

Figure 18

TSR (\%) FOR 2\%S

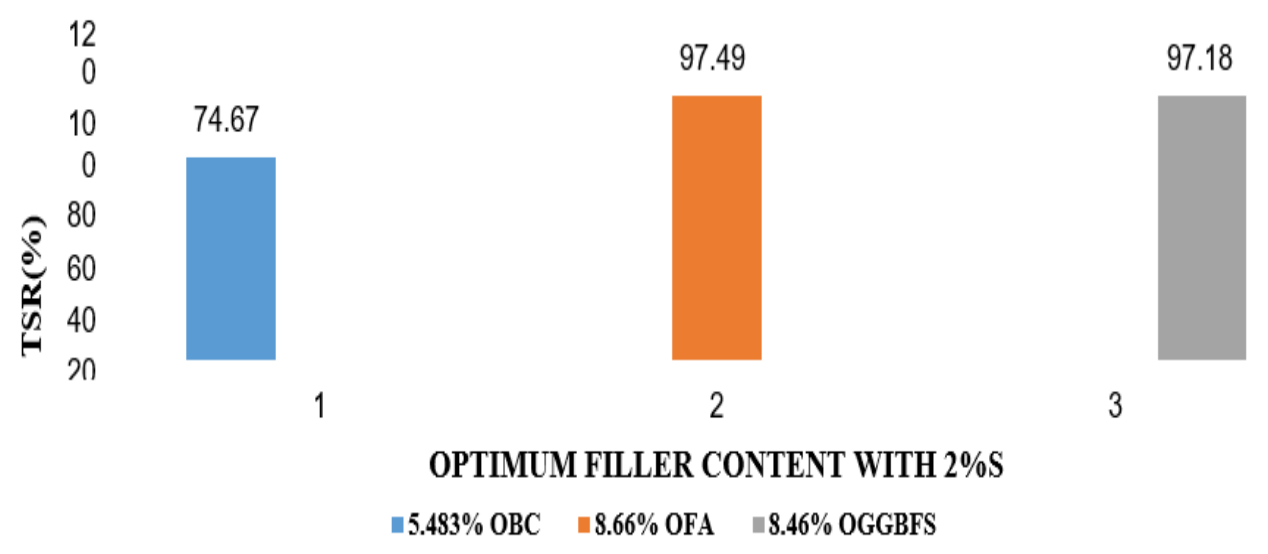

Figure 19 
- A series of indirect tensile tests were performed on OBC and OSC mixtures with different percentages of filler content (4\%-10\%) as Stone dust, Fly ash and GGBFS. The indirect tensile test for each mixtures is repeated three times to check the order of experimental results.

- By conducting ITS tests on OBC with varying filler contents as Stone dust, Fly ash and GGBFS, it is clear that the tensile strength of Virgin bitumen (VG 30) increases with different filler content. The TSR result for Control mix is lower as compared with two other fillers which is $71.071 \%$.By addition of Optimum filler contents such as fly ash (8.66\%) and GGBFS (8.46\%), it is erected that the GGBFS content provides maximum TSR results as compared with other two fillers. The TSR results for Stone Dust, Fly ash and GGBFS content on OBC are $71.071 \%, 85.55 \%$ and $91.858 \%$ respectively.

- The ITS results of OBC by using various fillers shows that GGBFS filler on OBC provides maximum TSR results which means it has less moisture susceptible and more resistance to moisture effect on bituminous mixture than other two fillers.

- By overseeing the ITS test results on OSC with individual filler contents as Stone dust, Fly ash and GGBFS, it is found that Fly ash as filler on sulfur modified binder gives maximum TSR value as compared with other two fillers which is $97.491 \%$. The TSR results for Stone dust, Fly ash and GGBFS content on OSC $(2 \%$ S) are $74.679 \%, 97.491 \%$ and 97.1875 respectively.

- Overally, it is concluded that Sulfur modified binder provides superior performance on ITS and TSR values as compared with Virgin bitumen. The filler as stone dust on both Virgin bitumen and Sulfur modified bitumen provide less TSR values which is also lesser than $80 \%$ which proves that Stone dust as filler in any bitumen binder has more moisture susceptible and less resistance to moisture effect. Fly ash and GGBFS as filler shows better results and also within the permissible limit which shows that these fillers have better quality than Stone dust.

\section{CONCLUSION}

This research study withdraws the following principal conclusions:

- The rising of modifier content have increases properties of sulfur. Moreover, variation in percentage of the sulfur modifier in bitumen also changes the physical properties reasonably. Penetration and softening point values are increased in increasing percentages of sulfur. The provision of less penetration and high softening point have been found as comparision among virgin bitumen. In addition of sulfur content, ductility and elastic recovery value are decreased and increased respectively. The effect of ageing of sulfur modified binder is within the acceptable range and provides better result as compared with virgin bitumen.

- By the use of sulfur, the strength and stability increases, reduces bitumen content and decrease the water induced damage. So that it is usable for pavement construction.

- By experimentation of susceptibility on moisture, physical, Mechanical and Volumetric features on Bituminous mixes accompanied with modifiers as sulfur, the optimum bitumen and sulfur content have been found out.

- With analyzing experimental result, sulfur content ( 0.5 to $4 \%$ ) constant with varying amount of bitumen as $4 \%, 4.5 \%, 5 \%, 5.5 \%$ and $6 \%$ by total weight of the mixture. It is noted that in sulfur modification $(0.5 \%-4 \%)$, the maximum Stability, Flow and bulk density of sulfur modified mixture is obtained at $2 \%$ sulfur content.

- The flow values of SMB mixtures within 2.5 to $4 \mathrm{~mm}$ which situated between specified limit as per IRC SP 53:2010. 
- While comparing with virgin bituminous mixture, Sulfur modified mixture is better than Control mixture.

- The sulfur modified bituminous mixture represents utmost stability on $2 \%$ amount of sulfur. As compared to control mixtures, Sulfur modifier replaced with Fly ash as filler provides greater power on tensile property and provide maximum resistance to cracking.

- The experimental outcomes shows that Optimum bitumen content (OBC) variations standing in need on category and quantity of modifiers. An incrementation of volume of sulfur within bituminous mixture, increases $\mathrm{OBC}$ first and then gradually decreases and then rises in a certain trend.

- The outcomes proves our objective in finding Optimum Fly ash and GGBFS content on Optimum sulfur as well as Optimum bitumen content providing satisfactory result as specified in MORTH.

- Modifiers sustains their individual extrusive activity to improve the tensile strength. So in this work, tensile strength is more on sulfur modification.

- The TSR value for Bituminous mixture with VG 30 bitumen without modifier has discovered as lower than $80 \%$ while in adding sulfur to mixture, Tensile strength ratio outcomes increases till $75 \%$ while using filler as Stone dust. By using flyash as well as GGBFS as filler, TSR value is more for sulfur modified mixtures as compared with Bituminous concrete mixtures with VG 30 bitumen. The research shows that sulfur modified mixtures replaced by Fly ash filler shows maximum TSR value as compared with other fillers in virgin as well as modified mixtures. The mixtures in the presence of sulfur modifier brings more stability, tensile strength with greater moisture resistance which protects the pavement from damages.

\section{REFERENCES}

[1] Das, A.K. and Panda, M., 2017. Investigation on rheological performance of sulphur modified bitumen (SMB) binders. Construction and Building Materials, 149, pp.724-732.

[2] Afifa Rahman, Syed Ashik Ali*, Sajal Kumar Adhikary and Quazi Sazzad Hossain: Effects of fillers on bituminous paving mixes: An experimental study, Journal of Engineering Science, ISSN , October 2012

[3] Ahmed Ebrahim Abu El-Maaty Behiry, "Laboratory evaluation of resistance to moisture damage In asphalt mixtures, Ain Shams Engineering Journal 4, 351-363 (2013).

[4] Ali Akbar Yousefi "Rubber-modified Bitumens", Publication at https://www.researchgate.net/publication/282642716, Iranian Polymer Journal September 2002

[5] Asphalt Mix design methods, Manual series No -2 (MS-2), Seventh edition.

[6] ASTM D 2872 (2004), "Standard Test Method for Effect of Heat and Air on a Moving Film of Asphalt (Rolling Thin-Film Oven Test)"

[7] ASTM D 4402. (2006). "Standard Test Method for Viscosity Determination of Asphalt at Elevated Temperatures Using a Rotational Viscometer".

[8] ASTM D6521, Standard Practice for Accelerated Aging of Asphalt Binder Using a Pressurized Aging Vessel (PAV).

[9] Bindu C.S, Dr. K.S Beena , "Waste plastic as a stabilizing additive in Stone Mastic Asphalt", ISSN,Vol - 2, 2010. 
Characterization of Sulfur Modified Binder Using Flyash and GGBFS as Filler Material

[10] Bituminous Mix design, NPTEL, Chapter-24.

[11] Civil Engineering Portal (CEP), https://www.engineeringcivil.com.

[12] Dr.S.K.Khanna,Dr. C.E.Justo,Dr. A.Veeraragavan, "Highway materials and pavement testing", Revised Fifth edition 2009.

[13] EN 14769: "Bitumen and bituminous binders - Accelerated long-term ageing conditioning by a Pressure Ageing Vessel (PAV)" (2005).

[14] Gawel, I. (2000). "Sulfur-modified asphalts", Journal of asphaltenes and asphalts, Elsevier Science Ltd, 2, 515-535.

[15] Ghaly, N. "Effect of Sulfur on the Storage Stability of Tire Rubber Modified Asphalt", World Journal of Chemistry, 3(2), 42-50 (2008).

[16] Guidelines on use of modified bitumen in road construction, IS:SP:53-2010 (Second Revision).

[17] tf. Kazemi Esfeh, B. Ghanavati, and T. Ghale Golabi, "Properties of Modified Bitumen ObtaIned from NATURAL Bitumen by Adding Pyrolysis Fuel Oil, InterNaTional JournaL Of Chemical Engineering AND Applications, Vol. 2 , No. 3 , June 2011.

[18] Haider Habeeb Aodah, Yassir N. A.Kareem, Satish Chandra, "Performance of Bituminous Mixes with Different Aggregate Gradations and Binders", International Journal of Engineering and Technology (IJET) - Volume 2 No. 11, November, 2012.

[19] http://www.sulphuric-acid.com/sulphuric-acid-on-the-web/news2018.htm:Cited on $30^{\text {th }}$ may 2019

[20] http://www.suyogsuppliers.com/ground-granulated-blast-furnace-slag-3130271.html.

[21] https://civilblog.org/2015/04/17/6-factors-influencing-aging-of-bitumen-binders

[22] https://civilseek.com/aggregate-definition-aggregates-types.

[23] https://en.wikipedia.org/wiki/Fly_ash.

[24] https://theconstructor.org/transportation/types-bitumen-mixes-pavements/16034

[25] https://www.slideshare.net/SushmithaSushie/aging-of-bitumen-33179661

[26] Indian Standard Methods of tests for aggregates for concrete, IS- 2386-Part -1.

[27] IRC SP: 53 -2002 Guidelines on Use of Polymer and Rubber Modified Bitumen in Road Construction", Indian Road Congress, New Delhi.

[28] IS 1203 (1978), "Methods for testing Tar and Bituminous materials, Penetration test, Bureau of Indian Standards, New Delhi.

[29] IS 1205 (1978), "Methods for testing Tar and Bituminous materials, Softening point test, Bureau of Indian Standards, New Delhi.

[30] IS 1208 (1978),"Methods for testing Tar and Bituminous materials, Ductility test, Bureau of Indian Standards, New Delhi. 
[31] Jyh-Dong Lin, Shih-Huang Chen, Pei Liu, \& Jian-Neng Wang: Modified Toughness used to Evaluate the Effect of Polymer Modified Asphalt on Stone Mastic Asphalt, Journal of the Chinese Institute of Engineers, vol. 27, No. 7, pp. 1013-1020, 2004.

[32] Mahabir Panda, Jhunarani OjhA, SiddharTh Purohit, "Development And Evaluation of Sulphur Modified Bitumen Binder," Proc.of the Eighth Intl. Conf. on Maintenance and Rehabilitation of Pavements, ISBN: 978-981-11-0449-7 :: doi:10.3850/978-981-11- 0449-7137-cd (2011).

[33] Manual No. M/85-150-P700Addendum No. D10-3311, Brookfield Engineering Laboratories, INC.

[34] Nuha S. Masha an, A.H.Ali, M. R. Karim and M.Abdelaziz, "Effect of Crumb Rubber concentration on physical and rheological properties of rubberized bitumen binder", ISSN Vol $6,2011$.

[35] P. Prajna S, M. Ilyas Anjum, "Suitability of sulphur as modifier in bitumen for road construction", IJRET, Volume 4, 2015.

[36] Praveen Kumar "Evaluation of Physical Properties of Sulfur Modified Bitumen and its Resistance to Ageing," Elixir Chem. Eng. 55A (2013) 13104-13107.

[37] Raha bitumen corporation, http://rahabitumen.com/bitumen-components

[38] S.A. Elkholy, A.M.M. Abd El-Rahman, M. El-Shafie, Z.L. Abo-Shanab, "Physical and rheological properties of modified sulfur asphalt binder," Egyptian Petroleum Research Institute (E.P.R.I.), Petroleum Applications Department, Asphalt Lab., Egypt, 1996-6814/_ 2018 Chinese Society of Pavement Engineering. Production and hosting by Elsevier B.V.

[39] Sabina, T. A Khan, Sangita, D K sharma, B.M Sharma, "Performance of critical analysis of waste plastic "Journal of scientific \& Industrial Research, Vol-68, 2009.

[40] Specifications for Road and Bridge works (MORTH).

[41] V.S.Punith and A.Veeraragavan: Behavior of Asphalt Concrete Mixtures with Reclaimed Polyethylene as Additive, Journal of Materials in Civil Engineering, Vol. 19, No.6,June1, 2007.

[42] Vahid Rezvani, Hassan Saghi; Characteristics and preparation method of sulphur extended asphalt mixtures, American Journal of Civil Engineering, 2015.

[43] Vishal Sharma,Satish Chandra, Rajan Choudhury: Characterization of Fly Ash Bituminous Concrete Mixes, Journals of materials in Civil Engineering, ASCE, December 2010.

[44] Wiktionary, https://en.wiktionary.org/wiki/maltene.

[45] Xiaohu Lu1, Yohann Talon, Per Redelius, “Aging of bituminous binders-Laboratory tests and field data", Nynas Bitumen, AB Nynäs Petroleum, SE - 149 82, Nynäshamn, Sweden 2 Ecole des Mines Nancy, 54042 Nancy Cedex, France 2001. 